\title{
Toxicity Assessment of Atrazine and Related Triazine Compounds in the Microtox Assay, and Computational Modeling for Their Structure-Activity Relationship *
}

\author{
P.B. Tchounwou1 ${ }^{1}$, B. Wilson ${ }^{1}$, A. Ishaque ${ }^{1}$, R. Ransome ${ }^{1}$, Ming-Ju Huang ${ }^{2}$ and Jerzy $^{\text {. }}$ \\ Leszczynski $^{2}$ \\ ${ }^{1}$ Environmental Toxicology Research Laboratory, NIH-Center for Environmental Health School of \\ Science and Technology, Jackson State University, P. O. Box 18540, Jackson, Mississippi 39217, \\ E-mail:paul@stallion.jsums.edu \\ ${ }^{2}$ The Computational Center for Molecular Structure and Interactions Department of Chemistry, \\ Jackson State University P. O. Box 17910, Jackson, Mississippi 39217, \\ E-mail: jerzy@tiger.jsums.edu
}

Received: 14 February 2000 / Accepted: 3 July 2000 / Published: 13 October 2000

\begin{abstract}
The triazines are a group of chemically similar herbicides including atrazine, cyanazine, and propazine, primarily used to control broadleaf weeds. About 64 to 80 million lbs of atrazine alone are used each year in the United States, making it one of the two most widely used pesticides in the country. All triazines are somewhat persistent in water and mobile in soil. They are among the most frequently detected pesticides in groundwater. They are considered as possible human carcinogens (Group C) based on an increase in mammary gland tumors in female laboratory animals. In this research, we performed the Microtox Assay to investigate the acute toxicity of a significant number of triazines including atrazine, atraton, ametryne, bladex, prometryne, and propazine, and some of their degradation products including atrazine desethyl, atrazine deisopropyl, and didealkyled triazine. Tests were carried out as described by Azur Environmental [1]. The procedure measured the relative acute toxicity of triazines, producing data for the calculation of triazine concentrations effecting 50\% reduction in bioluminescence $\left(\mathrm{EC}_{50} \mathrm{~s}\right)$. Quantitative structure-activity relationships (QSAR) were examined based on the molecular properties obtained from quantum mechanical predictions performed for each compound. Toxicity tests yielded $\mathrm{EC}_{50}$ values of $39.87,273.20,226.80,36.96,81.86,82.68,12.74,11.80$, and $78.50 \mathrm{mg} / \mathrm{L}$ for atrazine, propazine, prometryne, atraton, atrazine desethyl, atrazine deisopropyl, didealkylated triazine, ametryne, and bladex, respectively; indicating that ametryne was the most toxic chemical while propazine was the least toxic. QSAR evaluation resulted in a coefficient of determination $\left(\mathrm{r}^{2}\right)$ of 0.86 , indicating a good value of toxicity prediction based on the chemical structures/properties of tested triazines.
\end{abstract}

Keywords: Atrazine and triazines, Microtox, toxicity, QSAR 


\section{Introduction}

The use of pesticides in agriculture to boost food production is a major factor contributing to the degradation of our environment. The implementation of appropriate management strategies requires that adequate information be developed regarding the types, physical and chemical properties, fate, and toxicity of these pesticides.

Atrazine and other triazine herbicides constitute a group of chemically similar compounds used to control certain annual broadleaf weeds and grasses in North America and throughout the world. They are used primarily in corn, but also in sorghum, sugarcane, cotton, macadamia orchards, pineapple, asparagus, other crops, and landscape vegetation, to some extent. Atrazine has been estimated to be the most heavily used herbicide in the United States in 1987-89, with its most extensive use for corn and soybeans in several states including Illinois, Indiana, Iowa, Kansas, Missouri, Nebraska, Ohio, Texas, and Wisconsin [2].

All the triazine herbicides including atrazine, cyanazine, and propazine may be released into the environment through effluents discharge from manufacturing facilities, and through their use as herbicides. They are considered to be somewhat persistent in water, and mobile in soil. Because of their water solubility, they may leach into the ground water [3-4], as well as be transported in surface runoff [5]. Photodegradation and volatilization are of little significance under most field conditions. In the United States, monitoring studies of surface waters as well as ground waters have shown widespread detection of these herbicides [3,4, 6-10]. Surface water collected from 149 sites in 122 midwestern river basins indicated that $52 \%$ of the sites exceeded the United States Environmental Protection Agency's (U.S. EPA) maximum contaminant level (MCL) of $3 \mu \mathrm{g} / \mathrm{L}$ for atrazine [3].

The U.S. EPA considers atrazine as a systemic toxicant that has a potential of causing a variety of acute health effects including: congestion of the heart, lungs, and kidneys, hypotension, antidiuresis, muscle spasms, weight loss, and adrenal degeneration. Upon chronic exposure, atrazine also has the potential of causing weight loss, cardiovascular damage, retinal degeneration, and mammary tumors [2]. Similar health effects have been reported with exposure to other triazine compounds [11]. Because of the increase in incidence of mammary gland tumors in female laboratory animals exposed to triazine herbicides, these compounds are classified in Group C, and are therefore considered as possible human carcinogens [12]. The MCLs in drinking water are set at 3, 4, and $1 \mu \mathrm{g} / \mathrm{L}$ for atrazine, simazine, and cyanazine, respectively. The oral reference dose is set at $0.035 \mathrm{mg} / \mathrm{kg} / \mathrm{day}$ [13]. In the European Community, the health advisory for each triazine herbicide and metabolite is $0.1 \mu \mathrm{g} / \mathrm{L}$ for a total of 0.5 $\mu \mathrm{g} / \mathrm{L}$ in groundwater [14].

In many agricultural areas, triazine metabolites and transformation products such as desethyl atrazine and deisopropyl atrazine are also commonly found in surface and ground waters, together with their parent compounds [7, 14]. In a regional study of nine rivers in the Midwest Corn Belt, Thurman et al. [14] pointed out that desethyl atrazine (DEA), and deisopropyl atrazine (DIA) occur frequently in surface water that receive runoff from two parent triazine herbicides, atrazine and cyanazine.

However, little is known about the toxicological effects of triazine metabolites, and how their toxicity compares to that of the parent triazines. Moreover, no conceptual model has been developed to predict the toxicity of this important group of herbicides. Therefore, the objectives of this research were: 1) to assess the relative toxicity of major triazine herbicides, and their metabolic/biotransformation products, using the Microtox assay, and 2) to develop a computational 
model characterizing the structure-activity relationship of these triazines..

\section{Materials and methods}

\section{Reagents and Chemicals}

Lyophilized/freeze dried Microtox reagent (Vibrio fischeri) - Lot No. ACV014-2, osmotic adjustment solution (OAS) - Lot No. OAS007, reconstitution solution - Lot No. RSN006Y, and diluent - Lot No. DIL015L were purchased from Azur Environmental in Carlsbad, CA. Atrazine (2-chloro-4ethylamino-6-isopropylamino-s-triazine), atraton (2-ethylamino-4-isopropylamino-6-methoxy-striazine), ametryne (2-ethylamino-4-isopropylamino-6-methylthio-s-triazine), bladex (2-[4-chloro-6ethylamino-s-triazine-2-yl)-amino]-2-methyl propopionitrile), prometryne (2,4-bis[isopropylamino]-6methylthio-s-triazine), and propazine (2-chloro-4,6-bis[isopropylamino]-s-triazine), and some of their degradation products including atrazine desethyl (2-amino-4-chloro-6-isopropylamino-s-triazine), atrazine deisopropyl (2-amino-4-chloro-6-ethylamino-s-triazine), and didealkyled triazine (2-chloro4,6-diamino-s-triazine or atrazine desethyl desisopropyl) were purchased from Chem Service Inc. in West Chester, PA. Figure 1 presents the chemical structures of all these triazine herbicides. Dimethylsulfoxide (DMSO) was purchased from Sigma Chemical Company in St. Louis, MO.

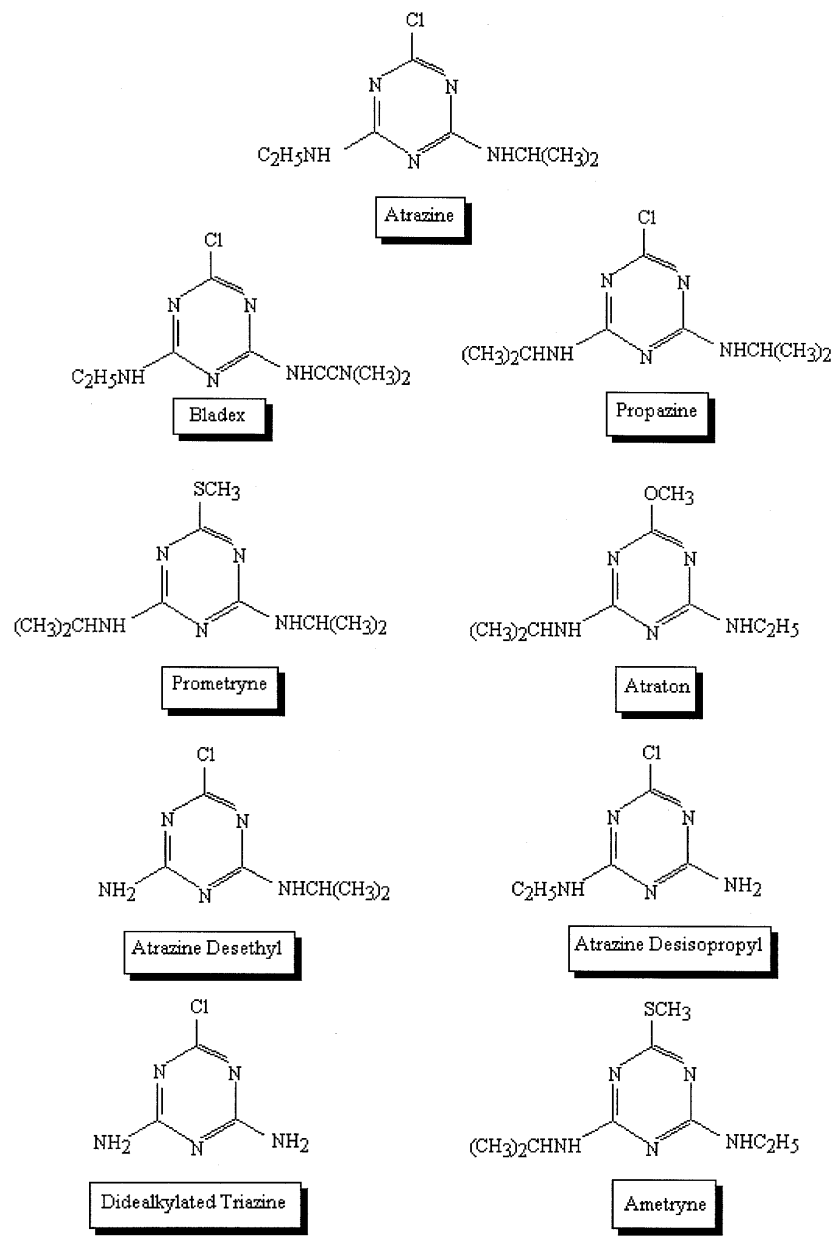

Figure 1. Chemical structures of the nine studied triazine herbicides. 


\section{Microtox System}

\section{Instrument}

This investigation was carried out with a Microtox Model 500 Toxicity Analyzer System (Azur Environmental, Carlsbad, CA). The instrument was equipped with a 30-well incubator block, a Reagent well and a Read well, all of which were temperature controlled by an internal incubation unit. Operating temperatures were internally regulated, and set at $5.5^{\circ} \mathrm{C} \pm 1^{\circ} \mathrm{C}$ for the reagent vials, and $15^{\circ} \mathrm{C} \pm 0.5^{\circ} \mathrm{C}$ for both the Incubator block and the Read well. Light output was read from the digital display.

\section{Microtox Acute Toxicity Assay}

Tests were carried out as described by Azur Environmental [1]. The procedure measured the relative acute toxicity of each triazine, producing data for the calculation of chemical concentration effecting $50 \%$ reduction of bioluminescence $\left(\mathrm{EC}_{50}\right)$. For each test run, 2 controls without herbicide, 8 sample dilutions and 2 replicates were done. Tests were carried out on 45.00, 22.50, 11.25, 5.63, 2.81, $1.41,0.70$, and $0.35 \%$ of the original triazine concentration $(200 \mathrm{pm})$ prepared in $5 \% \mathrm{DMSO}$. The test sample was adjusted with the osmotic adjustment solution (OAS) to insure that the final $\mathrm{NaCl}$ concentration in each test cuvette remained above $2.0 \%$. The test samples and diluent controls were equilibrated to the required temperature $\left(15^{\circ} \mathrm{C} \pm 0.5^{\circ} \mathrm{C}\right)$. For the reagent, $1 \mathrm{mg}$ of lyophilized/freeze dried Vibrio fischeri was hydrated in $1 \mathrm{~mL}$ reconstitution solution. $10 \mu \mathrm{L}$ of bacterial suspension were added, and the light outputs were measured before and after the desired incubation time (15 minutes). The diluent controls were run simultaneously, and the experiment was repeated 2 times.

\section{Quality Control}

The sensitivity of the strain of bioluminescent bacteria (Vibrio fischeri) was tested for quality control purposes. Phenol was used and tested in the Microtox assay to confirm the sensitivity of tester's strain over storage time. Data were then compared with the Microtox quality assurance guidelines [1].

\section{Data Analysis}

Results were calculated in terms of $Y$; i.e., the ratio of the light lost during test time $(t)$ to the light remaining at time $(t)$. A dose-response relationship curve was constructed by plotting the percentages of reduction in bioluminescence corresponding to $Y$ values against herbicide concentrations. The $E C_{50} S$ were determined as the concentrations corresponding to $50 \%$ decrease in light output $(\mathrm{Y}=1.0)$. Supporting computer software (Microtox version 7.3) with a standard log-linear model was used to calculate the effective concentrations $\left(\mathrm{EC}_{50} \mathrm{~s}\right)$.

\section{Quantitative Structure-Activity Relationship (QSAR)}

Atrazine and related triazine compounds were studied by semi-empirical AM1 quantum mechanical calculations with the Spartan program (SGI Version 5.1.1 OpenGL built under IRIX 6.2 workstation). 
Based on the AM1 optimized geometry and the van der Waals radii of each atom, the molecular surface, volume, and ovality were calculated using a previously described method [15-17].

The large size of the studied systems requires application of an efficient computational method. Two recent studies suggested that AM1 approach is accurate for triazine and related compounds. Creuzet and Langlet [18] after comparing the results from MP2/6-31G** and AM1 optimizations for striazine and diamino-triazine, concluded that AM1 calculations give accurate trends for the variation of geometrical parameters. Pankratov [19] compared semi-empirical MNDO, AM1 and PM3 methods. He calculated standard values of entropy, heats and Gibbs energies of formation, first ionization potentials and dipole moments for two series of compounds: 90 monocyclic and condensed bi-, tri- and polycyclic non-aromatic hydrocarbons and spirocyclic ones, 148 three-, five-, six- and sevenmembered nitrogen- oxygen-, sulphur-, selenium- and boron-containing unsaturated heterocycles. Linear dependences $P_{\text {exper }}=b P_{\text {theor }}$ (where $P$ is any of the mentioned properties) were observed. However, the sym-triazine was shown to be an example of unsuccessful reproduction of the heats of formation by AM1 method. Since in our study, we did not use the heats of formation for our parameters, we concluded that for the calculated properties, the accuracy of the AM1 method is expected to be adequate.

The $\log W$ (logarithm of the water solubility, units of moles/liter) value for each molecule was calculated by our BLogW program on a SGI IRIX 6.5 UNIX computer, and linear combinations of the calculated descriptors were fitted to the observed relative acute toxicity $\left(\log \mathrm{EC}_{50}\right)$ by using a regression program developed for UNIX computers.

$\log \left(\mathrm{EC}_{50}\right)=a+b(\log W)+c($ other descriptors $)$

and

$$
\log \mathrm{W}=\sum_{i} n_{i} P_{i}
$$

where the $P_{i}$ corresponds to the different molecular properties that we have developed for $\log W$. The "other descriptors" are those which may have an additional contribution to the activity.

\section{Results and Discussion}

\section{Microtox Assay}

Bioluminescence was used as endpoint for measuring the effect of triazine herbicides to $V$. fischeri. Figure 2 presents the dose-response graph obtained from the Microtox experiment with atrazine, the reference triazine herbicide. The examination of this graph indicates a gradual reduction in bioluminescence with increasing concentrations of atrazine. A similar trend was observed with the other eight tested triazine compounds. The $\mathrm{EC}_{50}$ values together with their $95 \%$ confidence limits, derived from the Microtox assay of the six tested triazine herbicides (atrazine, atraton, ametryne, bladex, prometryne, and propazine), and the three metabolites (atrazine desethyl, atrazine deisopropyl, and didealkyled triazine) are presented in Table 1. Data presented in this table indicate that all the triazine herbicides and their metabolic products exerted significant toxicity to Vibrio fischeri. This 
toxicity was evidenced by significant reductions in bioluminescence. $\mathrm{EC}_{50}$ values of 39.87, 273.20, $226.80,36.96,81.86,82.68,12.74,11.80$, and $78.50 \mathrm{mg} / \mathrm{L}$ were recorded for atrazine, propazine, prometryne, atraton, atrazine desethyl, atrazine deisopropyl, didealkylated triazine, ametryne, and bladex, respectively; indicating that ametryne was the most toxic chemical while propazine was the least toxic.

Table 1. Relative Toxicity of Atrazine, and Related Triazine Herbicides in the Microtox Assay.

\begin{tabular}{lcc}
\hline Chemical & $\mathbf{E C}_{\mathbf{5 0}}{ }^{*}$ & $\mathbf{9 5 \%}$ Confidence Limits (mg/L) \\
\hline Ametryne & 11.80 & $(11.45-12.10)$ \\
Atraton & 36.96 & $(35.08-38.94)$ \\
Atrazine (reference triazine) & 39.87 & $(35.37-44.93)$ \\
Atrazine Desethyl & 81.86 & $(77.26-86.74)$ \\
Atrazine Desethyl Desisopropyl & 12.74 & $(12.17-13.34)$ \\
Atrazine Desisopropyl & 82.68 & $(76.10-89.80)$ \\
Bladex & 78.50 & $(76.60-80.32)$ \\
Prometryne & 226.80 & $(193.40-266.2)$ \\
Propazine & 273.20 & $(154.20-484.10)$
\end{tabular}

*Effective concentration of herbicide needed to produce $50 \%$ reduction of bioluminescence

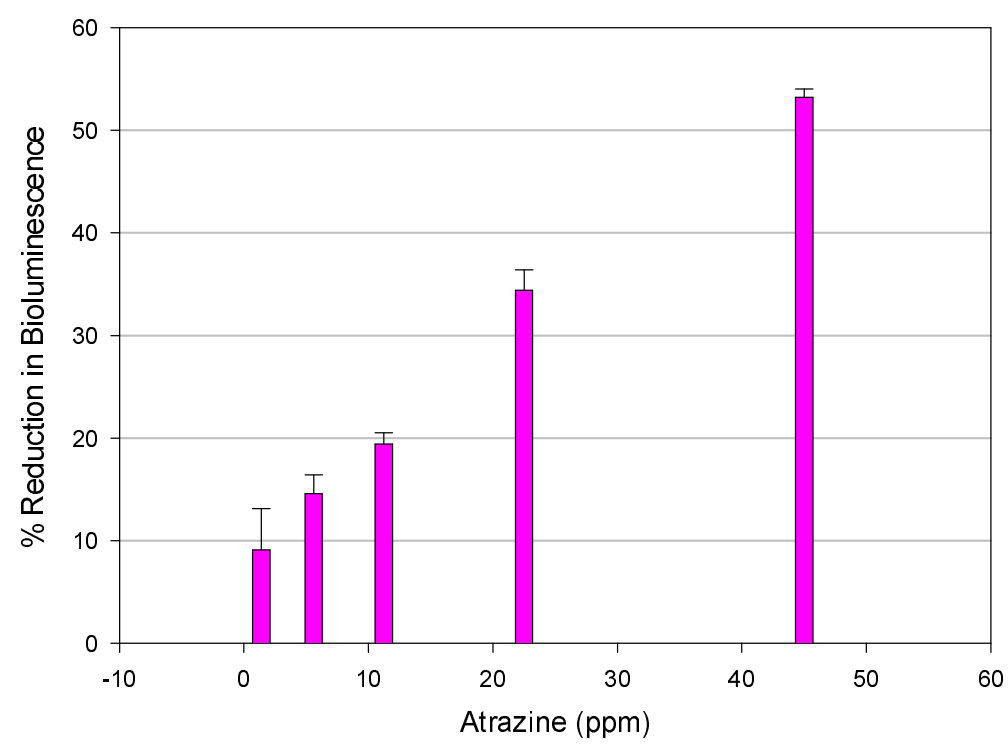

Figure 2. Effect of atrazine of the bioluminescence of Vibrio fischeri. 
The order of decreasing toxicity was ametryne, didealkylated triazine, atraton, atrazine, bladex, atrazine desethyl, atrazine deisopropyl, prometryne, and propazine. Among the three metabolites, didealkylated triazine was more toxic than atrazine while atrazine desethyl, and atrazine deisopropyl were less toxic; indicating a potential bioactivation in the case of didealkylated triazine, and a metabolic detoxification in the case of atrazine desethyl, and atrazine deisopropyl.

Quality control experiment with the positive phenol control detected no change in the sensitivity of Vibrio fischeri over the three weeks testing period. The mean $\mathrm{EC}_{50}$ value of phenol for three experimental data sets was $17.33 \pm 0.82 \mathrm{mg} / \mathrm{L}$, well within the expected range of 13 to $26 \mathrm{mg} / \mathrm{L}$ provided by the supplier of the test reagents [1]. The use of the Microtox assay in this research was based on the fact that this test system has been widely applied to assess the toxicity of a wide range of natural and anthropogenic pollutants [20-21]. It has been adapted to evaluate to toxicity of polluted waters, based on the utilization of the bioluminescence potential of a marine strain of bacterium, Vibrio fischeri [22-23]. The expression of bioluminescence is believed to reflect both cell density and cell viability. The test has been proved to be highly sensitive to various chemicals. This is due to chemical interactions with sensitive enzyme reactions mediated by an enzyme catalyst called luciferase [24], and the high sensitivity of a sophisticated instrument (Microtox analyzer) which uses photomultiplier tubes for light detection, rather than the traditional photometric method [25-26].

Previous studies on the adverse effects of atrazine, the reference triazine, indicated that this herbicide is acutely toxic to a significant number of freshwater organisms including phytoplankton [27-29], macrophytes [30-32], benthic organisms [33-34], zooplankton [35-36], and fish [37-38]. The degree of toxicity depends on several factors including the toxic endpoint analyzed (photosynthesis, growth, viability/survival), the duration of exposure, and the biological species involved. In general, phytoplancton have been reported to be most sensitive to atrazine toxicity, followed, in decreasing order of sensitivity, by macrophytes, benthic invertebrates, zooplancton, and fish [39].

\section{Quantitative Structure-Activity Relationship (QSAR) Analysis}

The numbering schemes for the general structure of the molecules studied are shown in Figure 3. We found that the best correlation is:

$$
\begin{aligned}
& \log \left(\mathrm{EC}_{50}\right)=-1.097 \log W-144.779 N 6-22.875 N 7-52.754 \\
& (n=9, F=10.2364, r=0.9274, S D=0.1796)
\end{aligned}
$$

Where $n$ is the number of compounds submitted to the regression; $r$ is the correlation coefficient; $S D$ is the standard deviation; and $F$ is the Fisher's variance ratio. The overall statistical significance of the equation, $\log W$ is the calculated $\log$ of the water solubility of the compound by using the BLogW program developed by Bodor and Huang [17]. N6 and N7 are the charge distributions for the N6 and $\mathrm{N} 7$ atoms. Both the calculated and the experimental values of $\log \mathrm{EC}_{50}$ are shown in Table 2. As mentioned in one of the environmental application notes on an internet website [40], the electron density resulting from the inclusion of the nitrogen in the ring and the diamino substituted groups impacts significant polarity to these compounds. Our QSAR studies show that the water solubility, the charge on N6, and the charge on N7 have negative influences on the $\mathrm{EC}_{50}$. Since the charges on N6 
and N7 are negative, this implies that the more the water solubility, the less negative charge on N6, and the less negative charge on $\mathrm{N} 7$, the smaller is the $\mathrm{EC}_{50}$.

Table 2. Computational Data Obtained from SAR Evaluation of Atrazine, and Related Triazine Herbicides.

\begin{tabular}{|c|c|c|c|c|c|}
\hline \multirow[b]{2}{*}{ Chemical } & \multicolumn{2}{|c|}{$\log \mathbf{E C}_{50}$} & \multirow{2}{*}{$\begin{array}{c}\log W \\
\text { (Calculated) }\end{array}$} & \multicolumn{2}{|c|}{ Charge Distributions } \\
\hline & Experimental & Calculated & & N6 & N7 \\
\hline Ametryne & 1.072 & 1.192 & -7.580 & -0.2734 & -0.2644 \\
\hline Atraton & 1.568 & 1.687 & -6.055 & -0.2867 & -0.2750 \\
\hline Atrazine & 1.601 & 1.845 & -6.974 & -0.2807 & -0.2758 \\
\hline Atrazine & 1.913 & 1.594 & -6.053 & -0.2856 & -0.2780 \\
\hline Desethyl & & & & & \\
\hline $\begin{array}{l}\text { Atrazine } \\
\text { Desethyl }\end{array}$ & 1.105 & 1.165 & -4.317 & -0.2853 & -0.3444 \\
\hline $\begin{array}{l}\text { Desisopropyl } \\
\text { Atrazine } \\
\text { Desisopropyl }\end{array}$ & 1.917 & 1.919 & -5.765 & -0.2799 & -0.3421 \\
\hline Bladex & 1.895 & 1.673 & -7.210 & -0.2760 & -0.2867 \\
\hline Prometryne & 2.356 & 2.266 & -7.780 & -0.2779 & -0.2733 \\
\hline Propazine & 2.436 & 2.521 & -7.326 & -0.2825 & -0.2771 \\
\hline
\end{tabular}

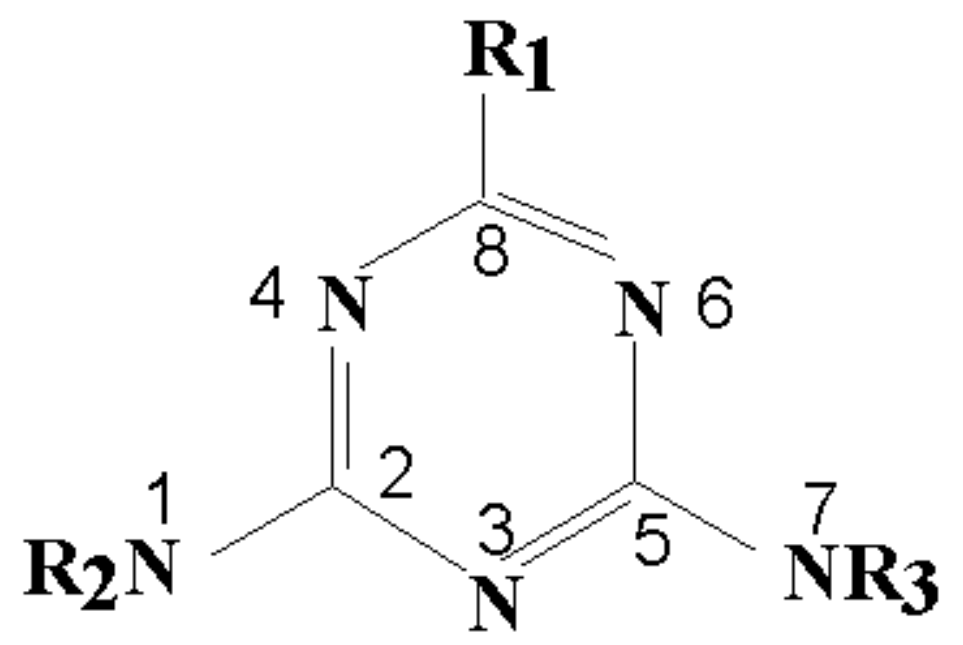

Figure 3. General molecular structure of tested triazine herbicides.

The evaluation of QSAR based on the above-defined concept of regression analysis resulted in a coefficient of determination ( $r$ ) of 0.93 (Figure 4), indicating a good value of toxicity prediction based on the chemical properties/structures of the tested herbicides. 


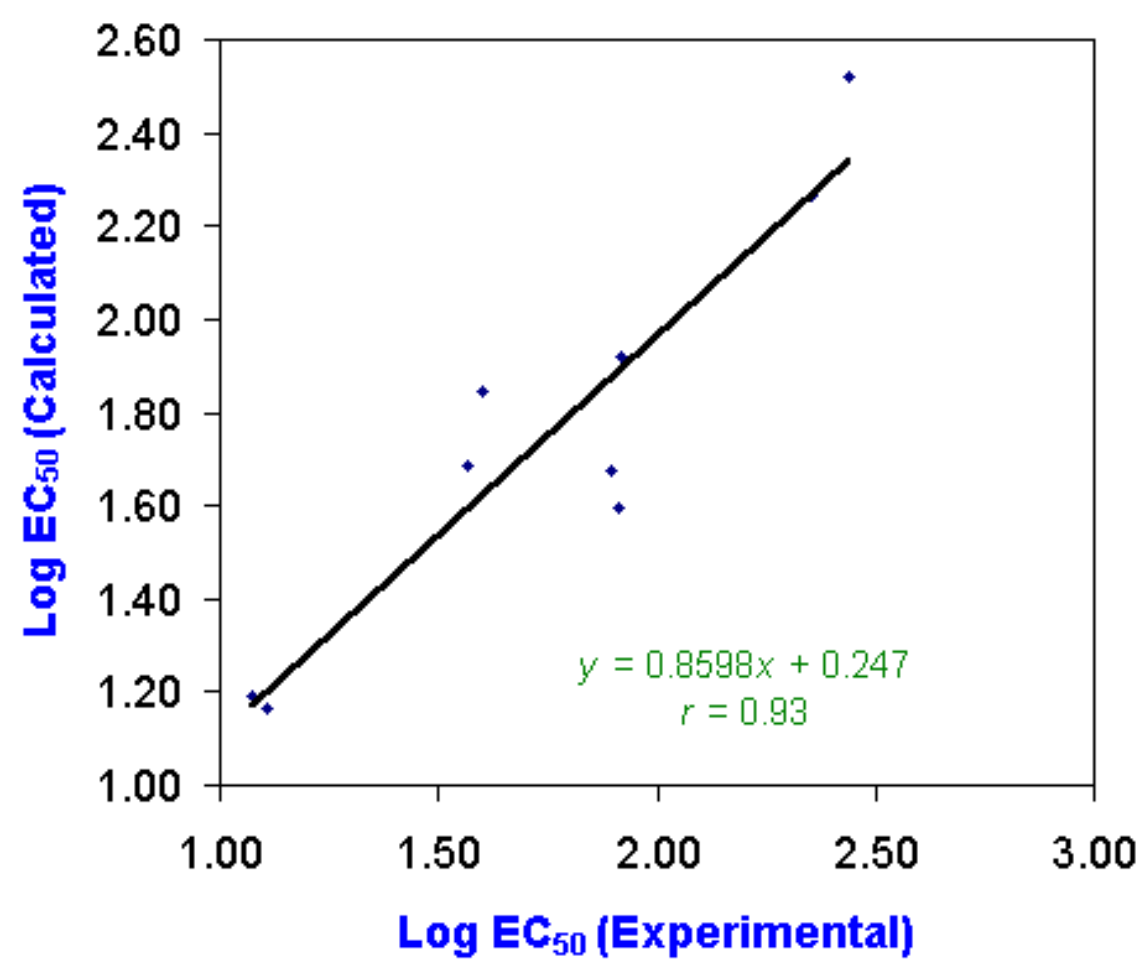

Figure 4. Model development for toxicity prediction based on the QSAR of tested triazines.

A review of literature indicates that there have been several QSAR studies done on herbicides. Biagi et al. [41] studied the lipophilicity indices of triazine herbicides. Oettmeier et al. [42] studied the SAR of triazinone herbicides on resistant weeds and resistant Chlamydomonas reinhardtii. Inhibition of photosystem II electron transport and SAR among herbicidally active 3-butenanilides were studied by Eilers et al. [43]. A 3D-QSAR study of anticoccidial triazines using the molecular shape analysis had been performed by Rhyu et al. [44]. They found that the steric shape and dipole moment of each analog governs its activity. A QSAR study of the inhibition of the Hill reaction by 2methylthio-4,6-bis(monoalkylamino)-1,3,5-triazines had also been done by Šoškić et al. [45]. So far, there are no other applications of QSAR in the toxicity of atrazine and related compounds based on the Microtox assay.

\section{Conclusions}

Results of this research clearly indicate that atrazine and related triazine herbicides are potent inhibitors of bioluminescence in the Microtox assay. The reduction of bioluminescence depends both on the chemical identity and concentration of each herbicide. Among the nine tested triazines, ametryne appeared to be the most toxic herbicide, while propazine was the least toxic one. The order of decreasing toxicity is as follow: ametryne, didealkylated triazine, atraton, atrazine, bladex, atrazine desethyl, atrazine deisopropyl, prometryne, and propazine. The analysis of QSAR results indicates that the potencies of the tested triazine herbicides were structure-dependent. A high value of linear correlation ( $r=0.93$ ) was recorded between calculated $\mathrm{EC}_{50} \mathrm{~S}$ generated from semi-empirical AM1 quantum mechanical computations, and experimental $\mathrm{EC}_{50} \mathrm{~s}$ derived from the Microtox Assay; indicating a good value of prediction of the activity/potency of studied triazines based on their molecular structures/properties. 


\section{Acknowledgments}

This research was financially supported through the Center for Environmental Health by a grant from the National Institutes of Heath (Grant No.1G12RR13459) to Jackson State University and through the Center for Molecular Structure and Interactions by a BEST Grant No. \# N62306-99-D-B004. We thank Dr. Abdul Mohamed for his technical support on this project. This paper has been presented at the "Eighth Conference on Current Trends in Computational Chemistry" in November 1999 in Vicksburg, Mississippi, USA.

\section{References}

1. Azur Environmental. Microtox - Acute Toxicity Basic Test Procedures. Carlsbad, CA. 1995.

2. U.S. EPA. Drinking Water and Health: Technical Fact Sheet on Atrazine. United States Environmental Protection Agency. Washington DC. 1999, on line at: http://www.epa.gov/ OGWDW/dwh/t-soc/atrazine.html

3. Thurman, E. M.; Goolsby, D. A.; Meye, M. T.; Kolpin, D. W. Herbicides in surface waters of the Midwestern United States: The effects of spring flush. Environ. Sci.Technol. 1991, 25, 1794-1796.

4. Thurman, E. M.; Goolsby, D. A.; Meyer, M. T.; Mills, M. S.; Pomes, M. L.; Kolpin, D. W. A reconnaissance study of herbicides and their metabolites in surface waters of the Midwestern United States using immunoassay and gas chromatography/mass spectrometry. Environ. Sci. Technol. 1992, 26, 2440-2447.

5. Grover, R.A. Environmental Chemistry of Herbicides. CRC Press. Boca Raton, Florida. 1988, pp. 45-88.

6. Coupe, R. H.; Thurman, E. M.; Zimmerman, L. R. Relation of usage to the occurrence of cotton and rice herbicides in three streams of the Mississippi Delta. Environ. Sci.Technol. 1998, 32, 3673-3680.

7. Kolpin, D. W.; Kalkoff, S. J.; Goolsby, D. A.; Sneck-Fahrer, D. A.; Thurman, E. M. Occurrence of selected herbicides and herbicide degradation products in Iowa's ground water 1995. Ground water 1997, 35(4), 679-688.

8. Kolpin, D. W.; Thurman, E. M.; Linhart, S. M. The environmental occurrence of herbicides: The importance of degradates in ground water. Arch. Environ. Contam. Toxicol. 1998, 1-6.

9. Squillace, P. J.; Thurman, E. M.; Furlong, E. T. Ground water as non point-source for atrazine and deethyl atrazine in a river during base flow conditions. Water Resources Res. 1993, 29(6), 17191729.

10. Squillace, P. J.; Thurman, E. M. Herbicide transport in rivers: Importance of hydrology and geochemistry of non point-source contamination. Environ. Sci.Technol. 1992, 26, 538-545.

11. U.S. EPA. Pesticides and Groundwater SMP Rule Technical support Document: Summary of Evidence of Adverse Human Health Effects for 5 SMP Candidates. Office of Pesticide Programs. United States Environmental Protection Agency. Washington DC. 1996, pp 1-30.

12. U.S. EPA. The Triazine Pesticides. United States Environmental Protection Agency. Washington DC. 1997, on line at: http://www.epa.gov/opp00001/citizens/triazine.html

13. IRIS. Atrazine-CARSN 1912-29-9. Integrated Risk Information System. Environmental Protection Agency. Washington DC. 1987, on line at: 
http://www.epa.gov/ ngispgm3/iris/subst/0209.html

14. Thurman, E. M.; Meyer, M. T.; Mills, M. S.; Zimmerman, L R.; Perry, C. A. Formation and transport of deethyl atrazine and deisopropyl atrazine in surface water. Environ. Sci.Technol. 1994, 28(3), 2267-2277.

15. Bodor, N.; Gabanyi, Z.; Wong, C.-K. A new method for the estimation of partition coefficient. $J$. Am. Chem. Soc. 1989, 111, 3783-3786.

16. Bodor, N.; Huang, M.-J. An extended version of a novel method for the estimation of partition coefficients. J. Pharm. Sci. 1992, 81, 272- 281.

17. Bodor, N.; Huang, M.-J. A new method for the estimation of the aqueous solubility of organic compounds. J. Pharm. Sci. 1992, 81, 954-960.

18. Creuzet, S.; Langlet, J. Theoretical determination of structural parameters for s-triazine and some derivatives. Comparison between ab initio and semi-empirical calculations. Chem. Phys. Lett. 1993, 208, 511-516.

19. Pankratov, A. N. Semi-empirical quantum chemical methods: testing of thermodynamic and molecular properties of cyclic non-aromatic hydrocarbons and unsaturated heterocycles. $J$. Mol.Struc. (Theochem) 1998, 453, 7-15.

20. Johnson, B. T.; Long, E. R. Rapid toxicity assessment of sediments from estuarine ecosystems: A new tandem in vitro testing approach. Environ. Toxicol. Chem. 1998, 17(6): 1099-1106.

21. Tchounwou, P. B.; Reed, L. Assessment of lead toxicity to the marine bacterium, Vibrio fischeri, and to a heterogenous population of microorganisms derived from the Pearl river in Jackson, Mississippi, USA. Rev. Environ. Hth. 1999, 14(2):51-61.

22. Al-Muzaini, S.; Beg, M. V.; Ali, L. N. Microtox assay for assessment of marine pollution in industrial discharge zone of Kuwait. Environ. Toxicol. Water Quality 1997, 12: 109-115.

23. Qureshi, A. A.; Coleman, R. N.; Paran, J. H. Evaluation and refinement of Microtox test for use in toxicity screening. In: Dutka BJ, Liu D eds. Toxicity Screening Procedures using Bacterial Systems. Toxicology Series, Vol. 1. Marcel Dekker, New York. 1984. P.1-22.

24. Nealson, K. H.; Hastings, J. W. Bacterial luminescence: Its control and ecological significance. Microbiol. Rev. 1979, 43, 496-518.

25. Hastings, J. W. Bacterial bioluminescence: An overview. In: Deluca M ed. Methods in Enzymology, Vol. 57. Academic Press, New York. 1978. pp 125-153.

26. Indorato, A. M.; Snyder, K. B.; Vsinowica, P. J. Toxicity screening using microtox analyzer, P. 37-53. In: Liu D, Dutka BJ eds. Toxicity screening using bacterial systems. Marcel Dekker, Inc., New York. N.Y. 1984.

27. Carder, J. P.; Hoagland, K. D.; Combined effects of alachlor and atrazine on benthic algal communities in artificial streams. Environ. Toxicol. Chem. 1998, 17(7), 1415-1420.

28. Tang, J.; Hoaglang, K. D.; Siegfried, B. Uptake and bioconcentration of atrazine by selected freshwater algae. Environ. Toxicol. Chem. 1998, 17(6), 1085-1090.

29. Veber, K.; Zahradnik, J.; Breyl, I.; Kredl, F. Toxic effects of atrazine on algae. Bull. Environ. Contam. Toxicol. 1981, 27, 872-876.

30. Hoberg, J. R. Atrazine-technical: Toxicity to duckweed (Lemna gibba). SLI Report 93-4-4755. Springborn Laboratories, Wareham, MA. 1993.

31. Kirby, M. F.; Sheahan, D. A. Effects of atrazine, isoproturon, and mesoprop on the macrophyte 
Lemna minor and the alga Scenedesmus subspicatus. Bull. Environ. Contam. Toxicol. 1994, 53, 120-126.

32. Lytle, J. S.; Lytle, T. F. Atrazine effects on estuarine macrophytes Spartina alterniflora and Juncus roemerianus. Environ. Toxicol. Chem. 1998, 17(10), 1972-178.

33. Macek, K. J.; Buxton, K. S.; Sauter, S.; Gnilka, S.; Dean, J. W. Chronic toxicity of atrazine to selected aquatic invertebrates and fishes. EPA-600/3-76-047. U.S. Environmental Protection Agency. Duluth, NM. 1976.

34. Streit, B.; Peter, H. M. Long term effects of atrazine to selected freshwater invertebrates. Arch. Hydrobiol. Suppl. 1978, 55, 62-77.

35. Oris, J. T.; Winner, R. W.; Moore, M. V. A four-day survival and reproduction toxicity test for Ceriodaphnia dublia. Environ. Toxicol. Chem. 1991, 10, 217-224.

36. Schober, U.; Lampert, W. Effects of sublethal concentrations of the herbicide atrazine on growth and reproduction of Daphnia pulex. Bull. Environ. Contam. Toxicol. 1977, 17, 269-277.

37. Davies, P. E.; Cook, L. S. J.; Goenarso, D. Sublethal responses to pesticides of several species of Australian freshwater fish and crustaceans and rainbow trout. Environ. Toxicol. Chem. 1994, 13, 1341-1354.

38. Kopriva, J. The toxicity of triazine and diazine based herbicides to fishes. Agrochemica 1981, 21, 344-347.

39. Solomon, K. R.; Baker, D. B.; Richards, R. P.; Dixon, K. R.; Klaine, S. J.; LaPoint, T. W.; Kenkdall, R. J.; Weisskopf, C. P.; Giddings, J. M.; Giesy, J. P.; Hall, L. W.; Williams, W. M. Ecological risk assessment of atrazine in north american surface waters. Environ. Toxicol. Chem. 1996, 15(1), 31-76.

40. Restek Corporation, Environmental Application Note \#59586: Analysis of Triazine herbicides. 1999. on line at: http://www.restekcorp.com/appnotes/59586.htm

41. Biagi, G. L.; Guerra, M. C.; Barbaro, A. M.; Recanatini, M.; Borea, P. A.; Sapone, A. Lipophilicity indices of triazine herbicides. Sci. Total Environ.. 1991, 109-110, 33-40.

42. Oettmeier, W.; Hilp, U.; Draber, W.; Fedtke, C.; Schmidt, R. R. Structure-activity relationships of triazinone herbicides on resistant weeds and resistant Chlamydomonas reinhardtii. Pesticide Sci. 1991, 33, 399-409.

43. Eilers, R. J.; Crouse, G. D; Durst, G. L.; Manly, C. J.; Webster, J. D.; Streusand, V. J. Inhibition of photosystem II electron transport and structure-activity relationships among herbicidally active 3-butenanilides, Pesticide Biochem. Physiol., 1992, 43(2), 162-170.

44. Rhyu, K. B.; Patel, H. C.; Hopfinger, A. J. A 3D-QSAR study of anticoccidial triazines using molecular shape analysis. J. Chem. Inf. Comp. Sci. 1995, 35(4), 771-778.

45. Šoškić, M.; Plavšić, D.; Trinajstić, N. Inhibition of the Hill reaction by 2- methylthio-4,6bis(monoalkylamino)-1,3,5-triazines. J. Mol. Struct. (Theochem), 1997, 394, 57-65.

(C) 2000 by MDPI (http://www.mdpi.org). 